\title{
Результаты деятельности фирмы в контексте специальных экономических зон: роль предпринимательской ориентации ${ }^{1}$
}

\section{Татьяна Шушарина *, Елена Гаффорова}

Дальневосточный федеральный университет, г. Владивосток, Россия

\author{
Информация о статье \\ Поступила в редакцию: \\ 15.04 .2020 \\ Принята \\ к опубликованию: \\ 15.06.2020 \\ УДК 330.3 \\ JEL L26
}

\begin{abstract}
Аннотация
В статье представлень результаты исследования фирм
Аннотация
В статье представлень результать исследования фирм малого и среднего бизнеса, функиионирующих в условиях особых институциональных режимов на Дальнем Востоке России. Эмпирическая проверка гипотез исследования проводилась на базе данных 128 компаний-резидентов специальных институциональных режимов, действуюших на Дальнем Востоке России. Полученные количественные оценки свидетельствуют о том, что в условиях особых экономических зон наблюдается положительная связь между предпринимательской ориентацией фирмы и результатов ее деятельности, обусловленной в большей степени инновационностью и проактивностью фирм.
\end{abstract}

Firm Performance in the Context of Special Economic Zones: the Role of Entrepreneurial Orientation

Tatyana Shusharina, Elena Gafforova

\begin{abstract}
The article presents the results of the study of small and medium-sized business firms operating under special institutional regimes in the Russian Far East. The objective of this study was to identify the effect of entrepreneurial orientation (i.e. risk taking, innovativeness and proactivity) on the firm performance in the context of special institutional regimes in the Far East of Russia. This theoretically derived research model is empirically validated by the survey data of 128 small and medium-sized enterprises-residents of special institutional regimes operating in the Russian Far East. The results obtained clearly indicate that entrepreneurial orientation positively influences upon the business performance.
\end{abstract}

(1)
Keywords:

entrepreneurship, entrepreneurial orientation, special economic zone, small and medium enterprises

${ }^{1}$ Статья выполнена на основе материалов научно-исследовательского проекта Лаборатории исследования предпринимательства Школы экономики и менеджмента ДФВУ № 0001-18И001 по теме «Влияние особых институциональных режимов на поведение и результативность компаний (на примере Дальнего Востока России)». Авторы выражают благодарность и глубокую признательность научному коллективу.

* Автор для связи: shusharina.te@dvfu.ru

DOI: https://dx.doi.org/10.24866/2311-2271/2020-1/65-80 


\section{Введение}

По мере того, как окружающая среда становится все более сложной и диверсифицированной, а страны все более взаимосвязанными благодаря усиливающейся глобализации, различия в экономических показателях и развитии между различными странами увеличиваются. Конкурентоспособность, безопасность и целостность государства зависит от уровня социальноэкономических условий и однородности территориального экономического развития внутри страны.

Как известно, в России условия для бизнеса отличаются в каждом регионе, в виду дифференцированности их потенциала по уровню социальноэкономического развития, исторических событий и других причин. Для выравнивания ситуации Правительством утверждаются новые экспериментальные механизмы для стимулирования деловой активности в отстающих и перспективных регионах, каким является Дальний Восток России.

Экономика Дальневосточного федерального округа (далее - ДФО) высокозатратна в силу слабого развития инфраструктуры, продовольственной зависимости [1], в связи с чем большое развитие получили сырьевые (рентные) отрасли экономики [2]. Вместе с тем перед макрорегионом поставлена задача стать плацдармом интеграции России в стремительно развивающийся Азиатско-Тихоокеанский регион (далее АТР). Это требует формирования новой модели ускоренного экономического развития ДФО, ориентированной на экспортно-ориентированный высокотехнологичный и наукоемкий сектор экономики.

24 октября 2013 г. на первом заседании Правительственной комиссии по вопросам социально-экономического развития Дальнего Востока одобрена новая модель опережающего развития Дальневосточного региона, которая направлена на создание в ДФО конкурентоспособных в масштабах АТР условий инвестирования и ведения предпринимательской деятельности, способствующих, в том числе переходу от сырьевой экономики к производству с более высокой добавленной ценностью.

В рамках данного решения в период с 2014 г. разработаны и запущены новые механизмы развития Дальнего Востока, такие как территории опережающего социально-экономического развития (далее - ТОСЭР, ТОР), Свободный порт Владивосток (далее - СПВ), программа «дальневосточный гектар», система выдачи электронных виз для иностранных граждан и другие. Особое внимание, на наш взгляд, с точки зрения влияния на предпринимательскую активность и выравнивание межрегиональных различий заслуживают инициативы по установлению особых экономических режимов ведения бизнеса на Дальнем востоке, а именно режимы ТОР и СПВ.

В международной практике данные режимы больше известны как специальные экономические зоны (Special Economic Zones, SEZs), основными целями которых являются увеличение внешнеторгового баланса, создание новых рабочих мест, привлечение иностранных инвестиций, передовых технологий производства товаров и услуг и апробация эффективных методов управления. Для привлечения инвесторов и предпринимателей к созданию в зоне новых предприятий вводятся особые режимы налогообложения, таможенные и тру- 
довые нормы, доступ к инфраструктуре, административные преференции.

Первые ТОР появились на Дальнем Востоке в 2015 г., тогда же был создан свободный порт Владивосток. Резиденты таких зон получают льготы взамен на инвестиции.

По официальным данным руководства АО «Корпорация развития Дальнего Востока» (КРДВ, управляющая компания территорий опережающего развития и свободного порта Владивосток) по состоянию на 05 февраля 2020 года 2193 резидента ведут свою деятельность на территориях ТОР и СПВ, из них 286 уже запустили свои проекты. Общий заявленный объем инвестиций составил более 3,8 трлн рублей, реализация заявленных проектов позволит создать около 156,8 тыс. рабочих, фактически вложено более 738,4 млрд рублей частных инвестиций, создано почти 37,5 тыс. рабочих мест [3].

Однако, несмотря на растущий интерес предпринимателей к преференциальным режимам, выраженным увеличивающимся количеством резидентов, и высокими декларируемыми результатами функционирования режимов, наряду с удовлетворенностью режимами ТОР и СПВ резидентами и предпринимателями отмечаются и проблемы, ставшие сдерживающими факторами развития инвестпроектов.

В ходе полевых исследований, анализа научных публикаций и открытых источников данных предпринимателями-резидентами ТОР и СПВ преимущественно отмечаются следующие трудности:

1. В части налоговых преференций:

- «нерабочие» льготы (например, ускоренный возврат НДС по резидентов на сегодняшний день не работает);

-риск отмены льгот;

2. В части инфраструктуры:

-отсутствие инфраструктуры на участках (резиденты ТОР могут рассчитывать на подведенную инфраструктуру, но нередко сталкиваются с тем, что на их участке нет некоторых коммуникаций);

-не достаточно развитая транспортная инфраструктура (по данным компании InfraOne, подготовившей индекс инфраструктурного развития российских регионов, уровень развития транспортной инфраструктуры в Дальневосточном федеральном округе ниже, чем в среднем по стране $(3,24),-3,02)$ [4];

3. В части других преференций:

-создание свободной таможенной зоны (далее - СТ3) требует огромных затрат и долгих согласований с таможенной службой;

-неэффективный процесс получения земельных участков.

Как известно, любая институциональная среда имеет ограничения, в том числе и режимы ТОР и СПВ. Несмотря на это, часть фирм успешно преодолевают существующие барьеры и добиваются целевых финансовых результатов, а другие компании, находясь в тех же условиях, терпят неудачу.

Одни предприниматели активно используют новые технологии, стремятся предлагать принципиально новые продукты и активно использовать открывающиеся возможности. Другие больше ориентированы на удержание имеющихся позиций. Фирмы с предпринимательской ориентацией можно охарактеризовать тем, насколько они нацелены на рост и развитие своего 
бизнеса. Предприниматели, нацеленные на получение конкурентных преимуществ, ищут и стремятся использовать инновационные идеи. Интенсивность конкуренции, возрастающее количество способов удовлетворения потребностей заставляют фирмы обновлять технологии производства и выводить на рынок инновационные продукты.

Анализом эффективности режимов ТОР и СПВ занимаются многие исследователи. Но исследования самих компаний-резидентов, их внутренних процессов управления, стратегического поведения, мотивов, восприятия специальных режимов хозяйствования практически отсутствуют.

В связи с чем было проведено исследование, в рамках которого изучалось поведение резидентов ТОР и СПВ и его влияние на результаты их деятельности с точки зрения современных концепций теории предпринимательства.

Целью данной статьи является выявление и оценка связи предпринимательской ориентации, а также ее отдельных конструктов с результатами деятельности фирм малого и среднего предпринимательства, функционирующих в рамках специальных институциональных режимов ТОР и СПВ. В рамках исследования предпринята попытка ответить на следующие исследовательские вопросы.

1. Как развитие в фирме предпринимательской ориентации связано с результатами ее деятельности в контексте специальных институциональных режимов?

2. Какова роль доступности финансового капитала в связи между предпринимательской ориентацией и результатами деятельности фирмы?

\section{Теоретическая основа и гипотезы исследования}

Одной из ключевых концепций в исследованиях предпринимательства на уровне фирмы - является концепция предпринимательской ориентации (далее - ПО) (Entrepreneurial Orientation - EO) [5]. На сегодняшний день предложено много определений $\mathrm{EO}$, но в данной работе авторы придерживаются основного определения, которое предложили основоположники концепции Ковин и Слевин [6], где «предпринимательская ориентация фирмы демонстрирует степень, с которой топ-менеджеры склонны принимать на себя бизнес-риски (компонент «принятие риска»), поддерживать организационные изменения и инновации для получения конкурентного преимущества для их фирмы (компонент «инновационность») и агрессивно конкурировать с другими фирмами (компонент «проактивность») [5, 6]. Предпринимательская ориентация характеризует предпринимательскую деятельность фирм, которая позволяет им искать, создавать и извлекать выгоду из новых возможностей для бизнеса $[7,8,9]$.

Инновативность относится к тенденции «участвовать и поддерживать новые идеи, новизну, эксперименты и творческие процессы, которые могут привести к появлению новых продуктов, услуг или технологических процессов» [9]. Это облегчает использование новых возможностей, вызванных изменениями внешней среды [8]. Инновационное поведение не обязательно подразумевает смелые, новые для мира инновации, но может подразумевать смешивание идей с инновациями, которые являются новыми для фирмы [10].

Проактивность отражает процесс «поиска новых возможностей, кото- 
рые могут быть, как связаны, так и не связаны с существующими направлениями деятельности фирмы, внедрением новых продуктов и брендов в ответ на растущий уровень конкуренции и стратегическим отказом/сокращением направлений деятельности или отдельных продуктов, которые находятся на стадии спада жизненного цикла» [11]. Высокий уровень проактивности фирмы помогает находить возможности на рынке, быстро и эффективно их использовать и получать высокую прибыль [12].

Принятие рисков подразумевает готовность выделять ресурсы на проекты с высоким уровнем неопределенности с целью получения высокой отдачи в будущем [9, 12], а также способствует активным и инновационным инициативам по изменению конкурентного ландшафта рынка [13].

Положительная связь предпринимательской ориентации (ПО) как стратегического поведения фирмы и результатов деятельности фирмы, подтверждается в широком диапазоне контекстов [14, 15 и др.].

Исследования показали, что фирмы внедряются в институциональный контекст [16] и что именно институциональная среда определяет стратегию, принятую фирмой [17]. В соответствии с исследованиями институциональной теории Rosenbusch et al. [18] показывают, что фирма должна принять стратегическое поведение, соответствующее требованиям его среды.

Воспринимая специальные институциональные режимы ТОР и СПВ, как среду, создающую новые реализуемые возможности, фирмы с предпринимательской ориентацией будут с большей вероятностью экспериментировать и расширять свою линейку новыми продуктами/услугами и выходить на новые рынки. Таким образом, предпринимательская ориентация делает фирмы более подготовленными к высокому уровню неопределенности внешней среды и позволяет более эффективно использовать имеющиеся у фирмы ресурсы для использования новых возможностей. Предпринимательская ориентация является также важным фактором для молодых и растущих фирм малого и среднего бизнеса, которая помогает им конкурировать с крупным устоявшимся бизнесом посредством достижения необходимого темпа роста и уровня конкурентоспособности [19].

Следовательно, можно предположить, что предпринимательски ориентированные фирмы малого и среднего бизнеса способны лучше извлекать выгоды, предоставляемые ТОР и СПВ, в то время как менее предпринимательские фирмы акцентируют внимание на угрозах и барьерах институциональной среды, сводя к минимуму использование благоприятных возможностей.

Гипотеза 1. Предпринимательская ориентация положительно связана с результатами деятельности фирм малого и среднего бизнеса в контексте специальных институциональных режимов ТОР и СПВ.

Инновационность проявляется в поиске новых идей, экспериментировании, проведении исследований и разработок, создании и запуске на рынок новых продуктов и услуг, внедрении новых процессов и методов ведения бизнеса, освоении новых сфер деятельности $[9,20]$. Исследования ряда ученых $[21,22,23]$ показали, что ориентированность на инновации и внедрение новых продуктов и услуг может быть эффективной стратегией фирмы для адаптации к неблагоприятной внешней среде и способствовать повышению 
ее конкурентоспособности на рынке. Для распознавания и реализации новых возможностей на рынке для компании важна проактивность, выражающаяся в готовности задавать тренды на рынке, изменении внешней среды, что является ключевым фактором конкурентоспособности фирмы [9]. Исследователи [24] отмечают тесную связь между проактивностью и инновационностью, так как проактивность зачастую позволяет фирмам быть на шаг впереди от конкурентов, опережая их в разработке и коммерциализации новых продуктов и услуг.

Инновационная и проактивная деятельность сопровождается рисками и предполагает готовность фирм вкладывать ресурсы в проекты, результаты которых сложно предсказать заранее [25].

Анализ исследований отдельных составляющих предпринимательской ориентации показывает разную связь каждой из них с результатами деятельности фирмы $[26,27]$. Сила данной взаимосвязи может зависеть от общего уровня экономического развития страны, институциональных условий и особенностей деловой среды. Как показано в исследовании [28] готовность к риску сильнее проявляется у компаний, функционирующих в странах с низким уровнем ВВП, средним уровнем развития технологий и инноваций и высокими экономическими рисками. Таким образом готовность к риску более свойственна фирмам развивающихся рынков с динамичной, сложной и враждебной средой, где фирмам приходится использовать возможности без учета имеющихся ресурсов, беря на себя высокие риски [26].

Также анализ исследований предпринимательской ориентации фирм развивающихся рынков показал более сильную положительную связь готовности к рискам и результатов деятельности фирм по сравнению с инновационностью и проактивностью $[26,29,30]$. С учетом приведенных выше аргументов, сформулирована вторая гипотеза.

Гипотеза 2. Каждая из компонент предпринимательской ориентации положительно связана с результатами деятельности фирм малого и среднего бизнеса в контексте специальных институцчиональных режимов ТОР и СПВ.

\section{Методология исследования и сбор эмпирических данных}

Исследование предпринимательской ориентации компаний-резидентов ТОР и СПВ и достигнутых результатов проводилось с помощью опроса владельцев и руководителей предприятий, входящих в ТОР и СПВ. Опрос проводился с апреля по июль 2018 г. Анкета для опроса резидентов была составлена на основе валидных шкал, апробированных и опубликованных ранее в высокорейтинговых научных журналах, а также самостоятельно составленных вопросов, валидность которых проверялась на пилотной группе респондентов, что позволило внести необходимые изменения и уточнения и минимизировать возможную неоднозначную интерпретацию вопросов на раннем этапе.

Сбор данных проходил с помощью комбинирования методов онлайнанкетирования, телефонного и личного интервью. Длительность опроса составляла от 60 до 90 минут. В ходе опроса гарантировалась анонимность ответов и указывалось, что результаты исследования будут опубликованы только в агрегированном виде.

Первоначально были проанализированы общедоступные реестры резидентов ТОР и СПВ, которых к моменту исследования насчитывалось в общей 
совокупности 820 фирм, на предмет актуальности статуса компании как резидента ТОР или СПВ, наличия телефонного номера и/или электронной почты руководства. В результате количество целевых фирм, которым предложили принять участие в опросе, составило 545 (у части компаний не удалось найти актуальные контактные данные для связи, другая часть прекратила свою деятельность в качестве резидента).

В выборке представлены частные предприятия малого и среднего бизнеса разной отраслевой принадлежности, допустимой для режимов ТОР и СПВ. Путем электронной рассылки респондентам, которые согласились пройти онлайн-анкетирование, была отправлена ссылка на стандартизированную анкету в Google-форме, что давало возможность интервьюеру отследить факт заполнения анкеты, отправить напоминание или дать пояснение с помощью телефонного звонка в случае необходимости. В результате было получено 128 заполненных анкет, что составило долю ответивших 15,6\% от выборки (табл. 1).

Распределение респондентов, ответивиих на анкету

\begin{tabular}{|l|c|c|c|}
\hline Резиденты & $\begin{array}{c}\text { Количество резидентов } \\
\text { на 25.03.2018 }\end{array}$ & $\begin{array}{c}\text { Количество резидентов с } \\
\text { контактными данными }\end{array}$ & $\begin{array}{c}\text { Количество } \\
\text { резидентов, } \\
\text { прошедших опрос }\end{array}$ \\
\hline ТОР & 248 & 126 & 29 \\
\hline СПВ & 572 & 419 & 99 \\
\hline Итого: & 820 & 545 & 128 \\
\hline
\end{tabular}

Источник: составлено авторами

Структура выборки по таким показателям как размер фирмы, eе расположение, отраслевая принадлежность и преференциальный режим представлена в табл. 2 .

Зависимая переменная. Для измерения результатов деятельности фирмы можно выделить объективные показатели, содержащиеся в статистических базах данных и архивных материалах, и субъективные показатели, отражающие мнение руководителей о результатах деятельности их фирмы [14]. В соответствии с целью исследования был использован субъективный показатель оценки результатов деятельности фирмы на основе анкеты, предложенной Stam и Elfring [31]. Респондентам было предложено оценить результаты деятельности их компании по сравнению с конкурентами, а именно: рост продаж, уровень прибыли, долю рынка, рост численности сотрудников. Каждый показатель оценивался по шкале Лайкерта от 1 до 7, где значение 1 обозначало «худшее положение фирмы по сравнению с конкурентами», 7 «лучшее положение фирмы по сравнению с конкурентами», и, соответственно, лучшие результаты деятельности фирмы соответствовали бо́льшим значениям по шкале. Использование субъективных оценок руководителями результатов деятельности их фирм нашло широкое применение в исследованиях $[12,14]$. Субъективное восприятие результатов деятельности фирмы также оправдано при исследовании фирм разной отраслевой принадлежности, так как используемые объективные показатели результативности (например, объем выручки, рентабельность, прибыльность) могут значительно различаться в 
зависимости от отрасли. Надежность полученных данных оценивалась с помощью коэффициента альфа Кронбаха, который составил 0,783. Как правило, коэффициенты надежности 0,70 или выше считаются адекватными [36].

Таблиия 2

\section{Структура выборки}

\begin{tabular}{|c|c|c|}
\hline Критерий & Категории & $\begin{array}{l}\text { Распределе- } \\
\text { ние фирм, \% }\end{array}$ \\
\hline \multirow{3}{*}{$\begin{array}{l}\text { Размер фирмы, } \\
\text { численность } \\
\text { работников }\end{array}$} & Микропредприятия (до 15 сотрудников) & 64 \\
\hline & Малые предприятия (от 16 до 100 сотрудников) & 26 \\
\hline & Средние предприятия (101-250 сотрудников) & 10 \\
\hline \multirow{10}{*}{$\begin{array}{l}\text { Отраслевая } \\
\text { принадлеж- } \\
\text { ность }\end{array}$} & Строительство & 23 \\
\hline & Предоставление прочих видов услуг & 20 \\
\hline & Обрабатывающие производства & 14 \\
\hline & Транспортировка и хранение & 11 \\
\hline & $\begin{array}{l}\text { Сельское, лесное хозяйство, охота, рыболовство и рыбо- } \\
\text { водство }\end{array}$ & 10 \\
\hline & $\begin{array}{l}\text { Деятельность гостиниц и предприятий общественного } \\
\text { питания }\end{array}$ & 8 \\
\hline & Деятельность по операциям с недвижимым имуществом & 4 \\
\hline & Добыча полезных ископаемых & 3 \\
\hline & $\begin{array}{l}\text { Деятельность в области культуры, спорта, организации } \\
\text { досуга и развлечений }\end{array}$ & 3 \\
\hline & Другое & 5 \\
\hline \multirow{7}{*}{$\begin{array}{l}\text { Расположение } \\
\text { фирмы }\end{array}$} & Приморский край & 78 \\
\hline & Хабаровский край & 7 \\
\hline & Камчатский край & 7 \\
\hline & Амурская область & 1,5 \\
\hline & Республика Саха (Якутия) & 1,5 \\
\hline & Чукотский автономный округ & 2 \\
\hline & Еврейская автономная область & 1 \\
\hline
\end{tabular}

Источник: составлено авторами

Независимая переменная. Для измерения предпринимательской ориентации фирмы была разработана порядковая шкала на основе шкал, представленных в работах [8; 32]. Шкала оценки ЕО была модифицирована с целью адаптации под исследуемый контекст и состояла из 7 вопросов, разработанных для оценки трех основных составляющих предпринимательской ориентации: инновационности, проактивности и принятия риска. Как отмечено в исследованиях $[14,33]$, удаление и/или изменение вопросов из оригинальной шкалы предпринимательской ориентации Ковина и Слевина [8] не является чем-то необычным и не влияет на ее достоверность. Аналогично модифицированные версии шкалы предпринимательской ориентации использовались в исследованиях [34, 35].

Респондентам предлагалось оценить каждое из представленных утверждений по трем компонентам ПО по шкале от 1 («полностью не согласен») до 7 («полностью согласен»). Значение коэффициента альфы Кронбаха для модернизированной шкалы предпринимательской ориентации составило 0,838. Проверка отдельных составляющих ПО также показала их приемлемость: 0,797 - для шкалы инновационности; 0,910 - для проактивности и 0,853 - для готовности к риску. Шкала ПО формировалась путем агрегирова- 
ния шкал инновационности, проактивности и принятия риска через расчет средневзвешенных величин [31, 37].

Контрольные переменные. Опираясь на исследования предпринимательской ориентации [7, 24, 37, 38] результаты деятельности фирмы могут варьироваться в зависимости от ее отраслевой принадлежности, размера, возраста, а также доступности финансового капитала.

Доступность финансового капитала фирмы была измерена с помощью шкалы, представленной в работе [22]. Шкала состоит из четырех вопросов, оценивающих наличие у фирмы финансовых ресурсов и их доступность для поддержания своей деятельности и финансирования бизнес-инициатив. Коэффициент альфа Кронбаха для шкалы составил 0,712.

Размер фирмы. Для адекватного сопоставления фирм в выборке размер фирмы был оценен как натуральный логарифм числа сотрудников [7, 37].

Отрасль. Для контроля различий в отраслевой принадлежности фирм было создано восемь бинарных переменных, каждая из которых обозначала принадлежит ли фирма к определенной отрасли (значение 1) или нет (значение 0): строительство; услуги; обрабатывающие производства; транспортировка и хранение; сельское, лесное хозяйство, охота, рыболовство и рыбоводство; гостиницы и общественное питание; деятельность по операциям с недвижимым имуществом; добыча полезных ископаемых; и прочие отрасли.

Шкалы измерения переменных, используемых в исследовании приведены в Приложении.

Описательная статистика и корреляционная матрица переменных, использованных в модели, представлена в табл. 3. В модели ПО рассматривается на уровне как единого конструкта, так и отдельных составляющих.

Таблица 3

Описательная статистика и корреляционная матрица

\begin{tabular}{|l|c|c|c|c|c|c|c|c|}
\hline \multicolumn{1}{|c|}{ Переменная } & $\mathbf{1}$ & $\mathbf{2}$ & $\mathbf{3}$ & $\mathbf{4}$ & $\mathbf{5}$ & $\mathbf{6}$ & $\mathbf{7}$ & $\mathbf{8}$ \\
\hline $\begin{array}{l}\text { 1. Результаты деятельности } \\
\text { фирмы }\end{array}$ & 1 & & & & & & \\
\hline 2. Финансовый капитал & $0,172^{* *}$ & 1 & & & & & & \\
\hline $\begin{array}{l}\text { 3. Размер фирмы (натураль- } \\
\text { ный логарифм) }\end{array}$ & 0,162 & 0,267 & 1 & & & & & \\
\hline $\begin{array}{l}\text { 4. Возраст фирмы (натураль- } \\
\text { ный логарифм) }\end{array}$ & 0,148 & 0,124 & 0,383 & 1 & & & & \\
\hline $\begin{array}{l}\text { 5. Предпринимательская } \\
\text { ориентация (ПО) }\end{array}$ & $0,367^{* *}$ & $0,183^{*}$ & $0,269 * *$ & $0,124^{*}$ & 1 & & & \\
\hline 6. Инновационность & 0,406 & $0,205^{*}$ & $0,231^{* *}$ & 0,122 & 0,736 & 1 & & \\
\hline 7. Проактивность & $0,246^{*}$ & 0,183 & $0,215^{*}$ & 0,147 & 0,795 & 0,703 & 1 & \\
\hline 8. Готовность к риску & 0,070 & 0,105 & 0,202 & 0,061 & $0,707 * *$ & $0,219^{* *}$ & & 1 \\
\hline Среднее значение & 4,08 & 2,92 & 2,47 & 1,30 & 4,95 & 5,46 & 5,02 & 3,99 \\
\hline Стандартное отклонение & 1,59 & 1,31 & 1,73 & 0,74 & 1,20 & 1,32 & 1,28 & 1,88 \\
\hline
\end{tabular}

Примечание: $\mathrm{n}=128 ; *-\mathrm{p}<0,05 ; * *-\mathrm{p}<0,01$

Источник: составлено авторами

На основе значений, представленных в корреляционной матрице, можно сделать вывод об отсутствии мультиколлинеарности в модели, поскольку коэффициенты попарной корреляции не превышают 0,8 . 


\section{Результаты анализа данных}

В качестве инструмента для проверки гипотез использовалась модель множественной линейной регрессии. Результаты регрессионного анализа приведены в табл. 4.

Таблийа 4

Результаты регрессионного анализа

\begin{tabular}{|l|c|c|}
\hline \multicolumn{1}{|c|}{ Переменная } & Модель 1 & Модель 2 \\
\hline Контрольные переменные & & $0,146^{* * *}$ \\
\hline Финансовый капитал & $0,097^{* * *}$ & 0,050 \\
\hline Размер фирмы (натуральный логарифм) & $-0,011$ & $0,207^{* *}$ \\
\hline Возраст фирмы (натуральный логарифм) & $0,200^{*}$ & Вкл. \\
\hline Отрасли (9) & Вкл. & \\
\hline Основные переменные & & $0,490^{* * *}$ \\
\hline Предпринимательская ориентация (ПО) & $0,493^{* * *}$ & $0,358^{* * *}$ \\
\hline Инновационность & & $0,049^{*}$ \\
\hline Проактивность & & \\
\hline Готовность к риску & & \\
\hline
\end{tabular}

Примечание: $n=128 ; * * *-p<0,001 ; * *-p<0,05 ; *-p<0,10$.

Источник: составлено авторами

В модели 1 рассматривается в качестве независимой переменной предпринимательская ориентация, рассчитанная в виде индекса на основе семи элементов. Оценка коэффициента при переменной является статистически значимой и положительной. Данный результат позволяет принять гипотезу 1.

Модель 2 включает в себя инновационность, проактивность и готовность к риску в качестве независимых переменных. Из тестируемых эффектов особо следует отметить значимость инновационности и проактивности. Положительный коэффициент говорит о том, что более высокий уровень инновационности и проактивности влечет за собой улучшение финансовых результатов деятельности фирмы. Оценка коэффициента готовности к рискам не является статистической значимой. Соответственно это позволяет принять гипотезу 2 лишь частично.

\section{Обсуждение полученных результатов}

В итоге проведенного исследования были выявлены положительные связи ЕО и двух ее оставляющих, а именно инновационности и проактивности, с результатами деятельности фирмы, в то время как подтвердить наличие такой связи для готовности к риску не удалось. Полученные выводы могут свидетельствовать о том, что отдельные составляющие ЕО могут быть поразному связаны с результатами деятельности фирмы в зависимости от контекста. Рядом исследований подтверждается положительная связь готовности к риску с результатами деятельности фирм на развивающихся рынках с враждебной и неблагоприятной внешней средой [26, 29, 30], при этом данная связь не подтвердилась в контексте специальных институциональных режимов ТОР и СПВ. С одной стороны, можно предположить, что среда специальных зон является более благоприятной и предсказуемой и у компаний нет необходимости проявлять готовность к риску. С другой стороны, возможно 
компании изначально «на входе» выбирают более прозрачную и благоприятную среду такую как ТОР и СПВ для максимального сокращения рисков. Данное предположение также подтверждается результатами проведенного в рамках данного исследования опроса, $84,3 \%$ из 128 резидентов ТОР и СПВ не ведут деятельность на зарубежных рынках, из них 60\% не планируют выходить на зарубежные рынки, 35\% ответили, что планируют выходить в течение ближайших 5 лет и 5\% планируют в течение года. Это можно объяснить тем, что выход на новые рынки связан с большой неопределенностью и повышенными рисками для компании, которые они не готовы нести.

Полученные результаты могут послужить основой для дальнейших исследований структуры предпринимательской ориентации в различных институциональных условиях функционирования фирмы, а также для исследования специальных институциональных режимов и стратегического поведения компаний-резидентов данных режимов.

\section{Заключение}

В результате исследования была выявлена положительная связь между ПО и результатами деятельности фирмы, наличие которой обусловлено в первую очередь инновационностью и проактивностью.

Результаты исследования могут быть полезны для исследователей в области предпринимательства в условиях особых институциональных режимов в контексте развивающихся рынков, а также для проведения сравнительного исследования предпринимательского поведения фирм в различных режимах и типах рынков. Теоретический вклад работы связан с тестированием взаимосвязи ПО и результатов деятельности фирмы в контексте развивающихся рынков в условиях особых институциональных режимов на уровне как одномерного, так и многомерного подхода к ПО. С практической точки зрения результаты исследования могут быть полезны собственникам и руководителям фирм с точки зрения применения соответствующих внешней среде моделей предпринимательского поведения.

Необходимо отметить ряд ограничений исследования. Во-первых, выборка фирм, использованных в исследовании, относится только к Дальневосточному федеральному округу, преимущественно к Приморскому краю. Это ограничивает возможность распространения выводов, полученных в рамках исследования, на фирмы, функционирующие в специальных экономических зонах, как России, так и других развивающихся рынков. Во-вторых, данные были собраны в один период времени, что не дает проследить изменения в предпринимательском поведении компании и оценить этот эффект в долгосрочной перспективе. В-третьих, основные переменные модели были измерены с помощью субъективной оценки участников опроса. В будущих работах может быть проведена репликация данного исследования с помощью объективных измерений переменных.

Тестирование модели исследования в условиях особых институциональных режимов позволит повысить внешнюю достоверность полученных выводов и уточнить роль контекста в предпринимательском поведении фирмы. 


\section{Список источников / References}

1. Заусаев В.К., Кручак Н.А., Бежина В.П. Новая модель роста Дальнего Востока. ЭKO, 2017, №2 (512). [Zausaev V.K., Kruchak N.A., Bezhina V.P. Novaja model' rosta Dal'nego Vostoka [New Far East Growth Model]. JeKO, 2017, №2 (512).]

2. Зубаревич Н.В. Социально-экономическое развитие регионов: итоги 2018 г. Экономическое развитие России, 2019, №3. [Zubarevich N.V. Social'nojekonomicheskoe razvitie regionov: itogi $2018 \mathrm{~g}$. [Socio-economic development of the regions: 2018 results]. Jekonomicheskoe razvitie Rossii, 2019, №3.]

3. Корпорация развития Дальнего Востока. [Korporacija razvitija Dal'nego Vostoka [Far East Development Corporation]. Available at: https://erdc.ru/news/dlyarezidentov-tor-i-spv-zapushchen-elektronnyy-servis-po-podache-otchetnosti-/ (accessed 15.04.2020).]

4. Инфраструктура России: индекс развития 2019. [Infrastruktura Rossii: indeks razvitija 2019 [Russian Infrastructure: Development Index 2019]. Available at: https://infraone.ru/analitika/Index_razvitiia_infrastruktury_Rossii_InfraONE_Research. pdf (accessed 15.04.2020).]

5. Широкова Г.В. Предпринимательская ориентация: истоки концепции и основные подходы к исследованию. Российский журнал менеджмента, 2012, №10 (3), cc. 55-72. [Shirokova G.V. Predprinimatel'skaja orientacija: istoki koncepcii i osnovnye podhody $\mathrm{k}$ issledovaniju [Entrepreneurial orientation: the origins of the concept and basic approaches to research]. Rossijskij zhurnal menedzhmenta $=$ Russian Management Journal, 2012, №10 (3), pp. 55-72.]

6. Covin J., Slevin D. The influence of organization structure on the utility of an entrepreneurial top management style. J. Manag. Stud., 1988, no. 25, pp. 217-234.

7. Беляева Т.В., Широкова Г.В., Гаффорова Е.Б. Результаты деятельности фирмы в период экономического кризиса: роль стратегических ориентаций и финансового капитала. Российский журнал менеджмента, 2017, №2 cc. 3-24. [Beljaeva T.V., Shirokova G.V., Gafforova E.B. Rezul'taty dejatel'nosti firmy v period jekonomicheskogo krizisa: rol' strategicheskih orientacij i finansovogo kapitala [The results of the company during the economic crisis: the role of strategic orientations and financial capital]. Rossijskij zhurnal menedzhmenta $=$ Russian Management Journal, 2017, №2 pp. 3-24.]

8. Covin J.G., Slevin D. Strategic management of small firms in hostile and benign environments. Strateg. Manag. J., 1989, no. 10, pp. 75-87.

9. Lumpkin G.T., and G.G. Dess. Clarifying the Entrepreneurial Orientation Construct and Linking It to Performance. Academy of Management Review, 1996, no. 21, pp. 135-172.

10. Perez-Luno A., Wiklund J. and Cabrera R. The dual nature of innovative activity: How entrepreneurial orientation influences innovation generation and adoption. Journal of Business Venturing, 2011, no. 26, pp. 555-571.

11. Venkatraman N. Strategic Orientation of Business Enterprises: The Construct, Dimensionality, and Measurement. Management Science, 1989, no. 35, pp. 942-962.

12. Wiklund J., and D. Shepherd. Entrepreneurial Orientation and Small Business Performance: A Configurational Approach. Journal of Business Venturing, 2005, no. 20, pp. $71-91$.

13. Covin J.G., Slevin D. A conceptual model of entrepreneurship as firm behavior. Enterp. Theory Pract, 1991, no. 16, pp. 7-25.

14. Rauch A., Wiklund J., Lumpkin G.T., Frese M. EO and business performance: an assessment of past research and suggestions for the future. Entrepreneurship Theory and Practice, 2009, no. 33 (3), pp. 761-787. 
15. Saeed S., Yousafzai S.Y., Engelen A. On cultural and macroeconomic contingencies of the entrepreneurial orientation-performance relationship. Enterp. Theory Pract., 2014, no. 38, pp. 255-290.

16. Engelen A., Flatten T.C., Thalmann J., Brettel M. The Effect of Organizational Culture on Entrepreneurial Orientation: A Comparison between Germany and Thailand. J. Small Bus. Manag., 2014, no. 52 (4), pp. 732-752.

17. Ingram P.L., Silverman B.S. The New Institutionalism in Strategic Management. Advances in Strategic Management, Elsevier., 2002.

18. Rosenbusch N., Rauch A., Bausch A. The mediating role of entrepreneurial orientation in the task environment-performance relationship a meta-analysis. J. Manag. 2013, no. 39, pp. 633-659.

19. Antoncic B., \& Hisrich R. D. Clarifying the intrapreneurship concept. Journal of small business and enterprise development, 2003, no. 10 (1), pp. 7-24.

20. Богатырева К., Широкова Г. Предпринимательская ориентация: этапы становления концепции и основные направления исследований. Российский журнал менеджмента, 2015, №13 (1), сc. 65-90. [Bogatyreva K., Shirokova G. 2015. Predprinimatel'skaja orientacija: jetapy stanovlenija koncepcii i osnovnye napravlenija issledovanij [Entrepreneurial orientation: stages of concept development and main research areas]. Rossijskij zhurnal menedzhmenta = Russian Management Journal, 2015, no. 13(1), pp. 65-90.]

21. Pearce J. A. II. Strategies to prevent economic recessions from causing business failure. Business Horizons, 2006, no. 49, pp. 201-209.

22. Story V.M. The form of relationship between firm-level product innovativeness and new product performance in developed and emerging markets / V.M. Story, N. Boso, J.W. Cadogan. Journal of Product Innovation Management, 2015, no. 32 (1), pp. 45-64.

23. Vanacker T. Slack resources, firm performance, and the institutional context: evidence from privately held European firms / T. Vanacker, V. Collewaert, S.A. Zahra. Strategic Management Journal, 2017, no. 38 (6), pp. 1305-1326.

24. Широкова Г., Богатырева К., Беляева Т. Предпринимательская ориентация российских фирм: роль условия внешней среды. Форсайт, 2015, №9 (3), сс. 6-25. [Shirokova G., Bogatyreva K., Beljaeva T. Predprinimatel'skaja orientacija rossijskih firm: rol' uslovija vneshnej sredy [Entrepreneurial orientation of Russian firms: the role of environmental conditions]. Forsajt $=$ Foresight, 2015, no. 9 (3), pp. 6-25.]

25. Zahra S.A. Predictors and Financial Outcomes of Corporate Entrepreneurship: An Exploratory Study. Journal of Business Venturing, 1991, vol. 6, no. 4., pp. 259-285.

26. Широкова Г.В., Богатырева К.А. Взаимосвязь предпринимательской ориентации и результатов деятельности фирмы: результаты исследования российских фирм малого и среднего бизнеса. Вестник С.-Петерб. ун-та. Сер. Менеджмент, 2014, №1, cc. 3-27. [Shirokova G.V., Bogatyreva K.A. Vzaimosvjaz' predprinimatel'skoj orientacii i rezul'tatov dejatel'nosti firmy: rezul'taty issledovanija rossijskih firm malogo i srednego biznesa [The relationship of entrepreneurial orientation and company performance: the results of a study of Russian small and medium-sized businesses]. Vestnik S.-Peterb. un-ta. Ser. Menedzhment, 2014, no. 1, pp. 3-27.]

27. Lecher C., Gudmundsson S.V. Entrepreneurial Orientation, Firm Strategy and Small Firm Performance. International Small Business Journal, 2014, vol. 32, no. 1, pp. 36-60.

28. Kreiser P.M., Marino L., Dickson P., Weaver M. Cultural Influences on Entrepreneurial Orientation: The Impact of National Culture on Risk Taking and Proactiveness in SMEs. Entrepreneurship Theory \& Practice, 2010, vol. 34, no. 5, pp. 959-983. 
29. Imrad Hameed B.A. Impact of Entrepreneurial Orientation, Entrepreneurial Management and Environmental Dynamism on Firm's Financial Performance. Journal of Economics and Behavioral Studies, 2011, vol. 3, no. 2, pp. 101-114.

30. Sharma A., Dave S. Entrepreneurial Orientation: Performance Level. Journal of Indian Management, 2011, vol. 8, no. 4, pp. 43-52.

31. Stam W., Elfring T. Entrepreneurial Orientation and New-Venture Performance: the Moderating Role of Intra- and Extraindustry Social Capital. Academy of Management Journal, 2008, vol. 51, no. 1, pp. 97-111.

32. Kyrgidou L.P., Petridou E. The effect of competence exploration and competence exploitation on strategic entrepreneurship. Technology Analysis \& Strategic Management, 2011, no. 23 (6), pp. 697-713.

33. Anderson B.S., Covin J.G., Slevin D.P. Understanding the relationship between EO and strategic learning capability: an empirical investigation. Strategic Entrepreneurship Journal, 2009, no. 3 (3), pp. 218-240.

34. Steensma H.K., Marino L., Weaver K.M., Dickson P.H. The influence of national culture on the formation of technology alliances by entrepreneurial firms. Academy of Management Journal, 2000, no. 43, pp. 951-973.

35. Runyan R.C., Ge B., Dong B., Swinney J.L. Entrepreneurial Orientation in CrossCultural Research: Assessing Measurement Invariance in the Construct. Entrepreneurship Theory and Practice, 2011, no. 36 (4), pp. 819-836.

36. Cronbach L.J. "Test Validation," in Educational Measurement, 2nd ed. Ed. R.L. Thorndike. Washington, DC: American Council on Education, 1971, pp. 443-507.

37. Широкова Г., Соколова, Л. Формирование предпринимательской ориентации в российских фирмах малого и среднего бизнеса: роль институциональной среды. Российский журнал менеджмента, 2013, №11 (2), сc. 25-50. [Shirokova G., Sokolova, L. Formirovanie predprinimatel'skoj orientacii v rossijskih firmah malogo i srednego biznesa: rol' institucional'noj sredy [Formation of entrepreneurial orientation in Russian small and medium-sized businesses: the role of the institutional environment]. Rossijskij zhurnal menedzhmenta $=$ Russian Management Journal, 2013, no. 11 (2), pp. 25-50.]

38. Madsen E. The significance of sustained entrepreneurial orientation on performance of firms - A longitudinal analysis. Entrepreneurship \& Regional Development, 2007, vol. 19, no. 2, pp. 185-204. 


\section{Шкалы измерения переменных}

Приложение

\section{Предпринимательская ориентация [8, 32]}

Пожалуйста, определите, в какой степени Вы согласны с приведенными ниже утверждениями относительно Вашей компании.

\section{Инновационность}

1. Обычно руководство компании одобряет решения, в которых делается акцент на исследования и разработки, технологическое лидерство и инновации.

2. Мы постоянно ищем возможности улучшения существующих продуктов.

3. Мы постоянно ищем возможности создания новых продуктов и услуг. Проактивность

4. По отношению к конкурентам наша компания, как правило, первой совершает действия на рынке, на которые реагируют конкуренты

5. По отношению к конкурентам наша компания часто является первой компанией в отрасли, которая вводит новые продукты/услуги, техники управления, технологии и т.д.

Готовность к риску

6. Как правило, руководство нашей компании склонно к реализации высоко рискованных проектов (с возможностью получения высокой прибыли)

7. В ситуации со многими неизвестными факторами компания занимает, как правило, смелую активную позицию для лучшего использования потенциальных бизнес-возможностей

\section{Результаты деятельности фирмы [31]}

Оцените результаты деятельности Вашей компании по сравнению с конкурентами по следующим параметрам:

1. Рост продаж;

2. Рост численности сотрудников;

3. Доля рынка;

4. Уровень прибыли.

\section{Доступность финансового капитала*}

Пожалуйста, определите, в какой степени Bы согласны с приведенными ниже утверждениями относительно Вашей компании.

1. Наша компания имеет легкий доступ к финансовому капиталу для поддержания своей деятельности.

2. Мы обладаем существенными собственными финансовыми ресурсами для финансирования бизнес-инициатив.

3. Наша компания имеет легкий доступ к иностранным инвестициям.

4. После вступления в ТОР/СПВ доступ к финансированию/кредиту заметно расширился.

*Вопросы 1-3 [22], вопрос 4 внесен для уточнения изучаемого контекста 


\section{Сведения об авторах / About authors}

Шушарина Татьяна Евгеньевна, старший преподаватель, исследователь Лаборатории исследований предпринимательства, Школа экономики и менеджмента, Дальневосточный федеральный университет. 690922 Россия, г. Владивосток, о-в Русский, кампус ДВФУ, корпус G. E-mail: shusharina.te@dvfu.ru

Tatiana E. Shusharina, Senior Lecturer, Researcher of the Entrepreneurship Research Laboratory, School of Economics and Management, Far Eastern Federal University. Building G, FEFU campus, Russky Island, Vladivostok, Russia 690920. E-mail: shusharina.te@dvfu.ru

Гаффорова Елена Борисовна, доктор экономических наук, доцент, профессор кафедры менеджмента, директор Школы экономики и менеджмента, исследователь Лаборатории исследований предпринимательства, Дальневосточный федеральный университет. 690920 Россия, г. Владивосток, о-в Русский, кампус ДВФУ, корпус G, каб. G609. E-mail: gafforova.eb@dvfu.ru Elena B. Gafforova, Doctor of Economic Sciences, Associate Professor, Professor of Department of Management, Director of the School of Economics and Management, Researcher of the Entrepreneurship Research Laboratory, Far Eastern Federal University. Office G609, Building G, FEFU campus, Russky Island, Vladivostok, Russia 690920.E-mail: gafforova.eb@dvfu.ru 